\title{
РОССИЙСКАЯ ПРАВОВАЯ ГОСУДАРСТВЕННОСТЬ НА ПЕРЕПУТЬЕ: ИСТОРИЧЕСКИЕ АСПЕКТЫ ВЫБОРА КОНЦЕПЦИИ ПРАВОВОГО ГОСУДАРСТВА В РОССИИ В КОНЦЕ 80-Х - НАЧАЛЕ 90-Х ГГ. ХХ В.
}

\begin{abstract}
Аннотация: Предметом исследования в настоящей статье является переломный исторический момент для истории становления правового государства в России - конеи 80-х-начало 90-х г2. ХХ в.. Автор прослеживает тот сравнительно короткий по историческим меркам промежуток времени, за который концепция правового государства прошла путь от первоначально осторожной имплементации в отечественную правовую модель в составе концепциии социилистического правового государства, до окончательного вытеснения всех конкурируюших концеепций (таких, как концеепция соцчиалистической законности) и утверждения в качестве флагмана отечественной политико-правовой мысли на грядущие десятилетия. Методологическую основу исследования составляет диалектический метод познания действительности, совокупность общенаучньх (логического, восхождения от абстрактного к конкретному в мышлении и т.д.) и частнонаучных методов познания (сравнительного правоведения, системно-структурного анализа, толкования закона и других). Исследуются основные вехи признания данной концепции на государственном уровне, в том числе в законодательстве позднего советского периода, направления научного осмысления концепции правового государства в правоведении начала 90-х гг. ХХ в. Характеризуются особенности трактовки данной концепции в различных проектах конституичии, разрабатывавшихся в тот период, в сопоставлении с окончательным вариантом текста, воплощенным в действующей Конституичей Российской Федераичи 1993 года.
\end{abstract}

Ключевые слова: Правовое государство, правовая государственность, сочиилистическое правовое государство, проекты конституичи РФ, Конституция РФ 19932., имплементация, социалистическая законность, идеология, монопартийность, парадигма.

Abstract: The subject of this research is the turning point in the history of establishment of the legal state in Russia during the late 80's and early 90's. The author follows the fairly short span of time during which the concept of legal state have transformed from the initial concept of a socialist legal state, to the final removal of all competing concepts (such as the concept of socialist legality) and establishment of domestic legal political thought as the flagship for coming decades. The author examines the key milestones of acceptance of this concept at the government level, including the legislation of the late post-Soviet period, and the vectors of scientific cognition of the concept of legal state within the legal sciences of the early 1990's. The author characterizes the peculiarities of the interpretation of this concept in the various constitutional projects developed in that time, as compared to the final version of the text embodied in the acting Constitution of the Russian Federation of 1993

Keywords: Legal state, Legal statehood, Socialist legal state, Constitutional projects of the Russian Federation, Russian Constitution, Implementation, Socialist legality, Ideology, Mono-party system, Paradigm.

конце 80-х - начале 90-х гг. ХХ века наша страна переживала уникальный период смены идеологических, правовых, политических, экономических, социальных и культурных ориентиров. Изменения затронули практически все сферы государственного и общественного бытия и были бы невозможными без смены тех «парадигмальных стержней», на которые опиралась каждая из этих сфер. В политической сфере происходил отказ от монопартийности, в идеологической - отказ от господства коммунистической идеологии, в экономической - отказ от плановой экономики. В правовой сфере таким «стержнем», который был «вынут»и заменен на новый, служил принцип социалистической законности, который был заменен на принцип правового государства.

На XIX Всесоюзной партийной конференции КПСС, прошедшей с 28 июня по 1 июля 1988 г. в г. Москве, курс впервые был взят на построение «социалистического правового государства». В ее резолюции говорилось: «Конференция считает делом принципиальной важности формирование социалистического правового государства как полностью соответствующей социализму формы 
DOI: $10.7256 / 1811-9018.2015 .8 .16129$

При цитировании этой статьи сноска на доі обязательна

\section{Право и политика 8 (188) $\bullet 2015$}

организации политической власти. Решение этой задачи неразрывно связано с максимальным обеспечением прав и свобод советского человека, ответственности государства перед гражданином и гражданина перед государством, с возвышением авторитета закона и строгим его соблюдением всеми партийными и государственными органами, общественными организациями, коллективами и гражданами, с эффективной работой правоохранительных органов. Коренная перестройка деятельности этих органов должна стать сердцевиной правовой реформы, которую конференция считает целесообразным провести в сравнительно короткие сроки» [1].

Зарубежные идеи правовой государственности, которые официально были взяты на вооружение и объявлены приоритетом в рамках правовой реформы, повлияли также на советскую законодательную практику, воплотившись в появлении и в советском законодательстве такого гибридного термина, как «социалистическое правовое государство». Одним из первых нормативных правовых актов, в которых закреплялся данный термин, были Основы законодательства Союза ССР и союзных республик о судоустройстве (приняты Верховным Советом СССР 13 ноября 1989 г.). Согласно части 2 статьи 3 данного документа, «вся деятельность суда направлена на всемерное укрепление социалистического правового государства, законности и правопорядка, утверждение принципа социальной справедливости, обеспечение демократизации и дальнейшего развития самоуправления народа, предупреждение правонарушений, воспитание граждан в духе точного и неуклонного исполнения Конституции СССР, конституций союзных республик, конституций автономных республик и советских законов, уважения к правам, чести и достоинству граждан, к правилам социалистического общежития» [2,С.7].

Казалось бы, следует только приветствовать восприятие российской правовой доктриной такой концепции, обладающей несомненным позитивным потенциалом, как правовое государство. Однако каждое событие следует рассматривать в его историческом контексте. В тот момент времени концепция правового государства оказалась противопоставленной концепции законности, что выразилось в смене отношения к действующему законодательству, возможности противопоставлять не только правовое государство - государству законности, но и право - закону.

Показательно, как менялось отношение ученых к действовавшей Конституции СССР 1977 г. под влиянием смены идеологически-правовых ориен- тиров. Наглядный пример приводит Ф.А. Вестов: «С.С. Алексеев, характеризуя в 1988 г. данную Конституцию как содержащую «вполне удовлетворительное решение» ряда вопросов правовой системы, уже через год говорил о декларативном, даже в какой-то степени лживом ее характере. При этом он предложил «создать первую настоящую юридическую Конституцию», закрепляющую как свободное существование советского государства, так и свободное, безопасное существование каждого человека» [1].

В проекте новой Конституции СССР 1990 года заявлялось о стремлении построить демократическое, социалистическое, гуманное общество, провозглашались правовое государство, образованное путем заключения Союзного договора, деятельность органов Союза на основе разделения трех властей, свобода СМИ и запрет цензуры, обязанность государства создавать условия, необходимые для развития разнообразных форм собственности и обеспечения их равной защиты[3,C.40-42].

Окончательно наша страна отринула как принцип социалистической законности, так и принцип социалистического правового государства в 1990 году, провозгласив ориентир на построение правового государства.

В частности, согласно Преамбуле Декларации о государственном суверенитете Российской Советской Федеративной Социалистической Республики (принята в г. Москве 12 июня 1990 г.) «Первый Съезд народных депутатов РСФСР ...торжественно провозглашает государственный суверенитет Российской Советской Федеративной Социалистической Республики на всей ее территории и заявляет о решимости создать демократическое правовое государство в составе обновленного Союза ССР».

Принятие этой Декларации и становление самостоятельной российской государственности дали стимул к поиску доктринальных основ ее дальнейшего правового развития в новом качестве. Как следствие - в начале 90-х гг. ХХ в. наблюдается новый всплеск интереса к концепции правового государства в отечественной правовой науке и механизмам ее практического воплощения. При этом для развития концепции правовой государственности в отечественной науке начала 90-х гг. XX в. характерны следующие черты. В условиях недостаточной разработанности категории правового государства в целом, история научного осмысления которой в применении к актуальной российской действительности, по сути, насчитывала лишь несколько лет, ученые, зачастую, концентрировались на исследовании смежной проблематики или отдельных составляющих правовой государственности, таких 
как проблема прав и свобод человека и гражданина, проблематика разделения властей, законности. Как отмечает Г.Д. Садовникова, «за годы Советской власти, вплоть до 1988 года в нашей стране было крайне мало серьезных исследований теории правового государства, поскольку, исходя из догм господствующей государственной идеологии, охватывающей все стороны жизни общества, в том числе и научную, концепция правового государства определялась как бесцеремонно подменяющая философско-юридический характер государства политико-правовым и использующаяся буржуазией как идеологическое оружие в борьбе против пролетариата» $[4, \mathrm{C.5}]$.

Например, В.В. Ершов в 1992 году концептуально исследовал роль и значение судебной власти в становлении правовой государственности. Автор справедливо отмечал, что «теоретическое обоснование, законодательное закрепление и практическое воплощение радикальной судебной реформы является существенной и необходимой общего процесса формирования правового государства в России» [5,С.2].

Г.Н. Беленов в 1991 году, исследуя категорию советского правового государства, полностью сосредотачивался на состоянии и развитии прав человека, отмечая, как приметы времени, что «усиливающийся социальный и политический кризис приводит к снижению уровня социальной защищенности трудящихся. Вследствие так называемой «войны законов» и связанный с нею юридической неопределенностью в решении многих жизненных вопросов появились признаки неустойчивости правового статуса граждан, снижается уровень гарантий прав и свобод личности. Сегодня необходимо признать состояние законности в стране как кризисное. Ухудшаются дисциплина и общественный порядок, массовый характер приобретает пренебрежение законами, как союзными, так и республиканскими. Все это влечет за собой рост преступности, создает угрозу личной безопасности граждан. Новые государственные структуры оказались неспособными обеспечить условия для стабильного развития общественных процессов, укрепления режима законности» [6,С.2].

А.Б. Лисюткин в 1992 году обращался к исследованию принципов законности, ее различных аспектов, роли в формировании демократического правового государства. При этом автор рассматривал законность как «общечеловеческую и общекультурную ценность, отражающую идеи равноправия, гуманизма, социальной справедливости», о чем свидетельствуют, по его мнению, принципы законности как «исходные основополагающие начала, заложенные в данном понятии (единство, общеобязательность, связь с культурностью, недопустимость противопоставления законности и целесообразности, верховенство закона, неотвратимость наказания за противозаконные деяния и др.» [7,С.6].

Между тем, несмотря на очевидную связь категорий правового государства и законности, разделения властей, прав и свобод человека и гражданина, они неравнозначны. В частности, хотя правовое государство предполагает развитую системы прав и свобод человека, совершенный механизм их законодательного закрепления и эффективные государственные гарантии, все же правовая государственность как таковая - явление более широкое и этим далеко не исчерпывается. Действенная система разделения властей также является одним из залогов сильного правового государства, однако не единственным. Законность же, исходя из механизмов соотношения закона и права, как таковая соотносится с верховенством права как форма и содержание. Однако правовое государство не равно государству законности, это также не совпадающие полностью по своему объему правовые категории, в связи с чем проблематика правовой государственности не исчерпывается проблематикой законности.

Таким образом, в начале 90-х гг. ХХ в. наблюдалась потребность в комплексной концептуальной проработке именно категории правовой государственности как таковой. Эта потребность особенно явно «встала на повестку дня» после того, как концепция правового государства утвердилась в качестве ориентира развития российской государственности на самом высоком конституционном уровне в связи с принятием Конституции Российской Федерации 1993 года.

Показательно, что в ходе длительного обсуждения конституционных проектов, предшествовавшего этому событию, предлагались различные варианты закрепления принципа правовой государственности.

Например, уже в преамбуле так называемого «саратовского проекта» конституции, подготовленного кафедрой государственного права Саратовского юридического института им. Д.И. Курского, закреплялось, что граждане Российской Федеративной Республики принимают Конституцию, «твердо решив создать демократическое правовое государство». Тем самым подчеркивалась значимость концепции правового государства для будущего государственного строительства. В действующей Конституции Российской Федерации преамбула такого указания не содержит. Сходством же «саратовского проекта» с действующим вариантом является характеристика России в качестве правового государства уже в первой статье. 
DOI: $10.7256 / 1811-9018.2015 .8 .16129$

При цитировании этой статьи сноска на доі обязательна

\section{Право и политика 8 (188) 2015}

Проект Конституции Российской Федерации, подготовленный Конституционной комиссией Съезда народных депутатов Российской Федерации [8], имел следующую важную особенность - наличие статьи 3 , озаглавленной как «Верховенство права». Вместе с тем, хотя в действующей Конституции заголовки статей отсутствуют и формально подобной статьи нет, содержание ее примерно соответствует содержанию статьи 15 Конституции Российской Федерации, за некоторыми нюансами.

В частности, в рассматриваемом проекте предполагалась следующая формулировка: «государство и его органы, органы местного самоуправления, предприятия, учреждения, общественные объединения, должностные лица и граждане подчинены праву и основанной на нем Конституции Российской Федерации». Как известно, действующая редакция части 2 статьи 15 Конституции Российской Федерации закрепляет, что «органы государственной власти, органы местного самоуправления, должностные лица, граждане и их объединения обязаны соблюдать Конституцию Российской Федерации и законы». Тем самым, в действующем варианте исправлено то противопоставление права и Конституции, которое намечалось в проекте Конституционной комиссии (по сути, он предполагал, что возможна и конституция, не основанная на праве, т.е. проводилась концепция возможности существования «неправового закона», в противовес концепции соотношения права и закона как сущности и формы).

Проект Конституции Российской Федерации, подготовленный рабочей группой под руководством С.М. Шахрая [9] вообще прямо не использовал термин «правовое государство», однако широко раскрывал принцип ограничения государства, который считается краеугольным камнем самой концепции правового государства. Например, постулировалось, что «государство в лице органов государственной власти не вмешивается в дела гражданина и общества, кроме как в рамках, определенных настоящей Конституцией», «законодатель ограничен основами конституционного строя, естественными и неотъемлемыми правами и свободами человека, обязательствами, принятыми на себя Российской Федерацией по заключенным международным соглашениям. Исполнительная и судебная власти ограничены также и законом» (части 1, 2 статьи 44 проекта).

Проект Конституции РФ, подготовленный по решению Политсовета Российского движения демократических реформ (Ответственный за подготовку член Политсовета А.А.Собчак. Авторская разработка проекта - С.С.Алексеев и А.А.Собчак при участии Ю.Х.Калмыкова, С.А.Хохлова) [10] также поместил отсылку к принципу правового государства уже в преамбулу. В частности, в ней предлагалось провозгласить, что народ Российской Федерации исполнен решимости образовать «правовое демократическое светское государство свободного сообщества свободных граждан». Особое место концепции правового государства, которое отвели ему авторы проекта, подтверждается и тем, что она вновь упоминается в первой же статье, согласно которой «Россия утверждает себя как правовое демократическое светское государство, высшими ценностями которого являются человек, его единство, неотъемлемые права и свободы». И вновь - в части 4 статьи 24 проекта, согласно которой «Конституционное устройство республик, организация государственной власти и местного самоуправления в губерниях и автономных национальных сообществах должны соответствовать принципам правового, демократического и светского государства в духе Конституции». Часть 2 статьи 76 проекта предусматривала, что «не могут быть предметом пересмотра положения Конституции, вытекающие из особенностей Российской Федерации как правового демократического светского государства, не признающего милитаристских целей в своей политике, а также положения Конституции об основных правах и свободах человека». В целом проект Российского движения демократических реформ является одним из наиболее широко проводивших концепцию правового государства.

Наконец, проект Конституции (Основного закона) Российской Федерации, представленный Президентом Российской Федерации [11], не упоминал принципа правового государства в преамбуле, однако также поместил его в первую же статью, согласно которой «Российская Федерация - Россия есть демократическое правовое светское федеративное государство, высшими ценностями которого являются человек, его достоинство, неотъемлемые права и свободы». Как и в действующей Конституции Российской Федерации, это единственная прямая отсылка в этом проекте к концепции правового государства.

Таким образом, несмотря на все различия, общим для всех рассмотренных проектов было признание основополагающей роли концепции правового государства как ориентира дальнейшего развития самостоятельной российской государственности, необходимости прямого или косвенного его закрепления в Конституции Российской Федерации. В научных исследованиях того 
времени также обосновывалось, что «одним из важных условий, обеспечивающих активное воздействие Конституции на процесс формирования правового государства, видится закрепление в тексте Основного Закона функционирования Российской Федерации как правового государства. Это ...обязывало бы все государственные органы, общественные объединения, должностных лиц и граждан руководствоваться в своей производственной деятельности и повседневной жизни критериями и принципами правового государства. Все нормативные акты и правительственные решения, в таком случае, также должны соответствовать этим принципам» [4,C.10].

Весь исторический период начала конституционной реформы в России В.Т. Кабышев очень метко назвал «периодом романтического конституционализма». В той уникальной исторической ситуации понятен энтузиазм, охвативший научное и законотворческое сообщество, причастное к разработкам проектов Конституции, стремление к правовой реконструкции общества на новой доктринальной основе. Концепция правового государства казалась одной из тех идей, само закрепление которых на высшем конституционном уровне способно изменить жизнь к лучшему. Однако, последовавший затем период нестабильности, отката назад по сравне- нию с советским периодом в уровне государственных гарантий прав и свобод человека и гражданина во многих ключевых сферах (таких, как социальная и культурная, частично экономическая) показал, что правовой идеализм, конечно, необходим для того, чтобы «толкать вперед» государственную машину, однако должен во время сменяться правовым реализмом.

Первые годы после принятия Конституции Российской Федерации ознаменовались появлением ряда крупных научных работ по проблеме правового государства, в которых на комплексной научной основе разрабатывалась доктрина правовой государственности $[12,13,14,15,16,17,18]$.

Таким образом, концепция правового государства в России в конце 80-х - начале 90-х гг. за сравнительно короткий по историческим меркам промежуток времени прошла путь от первоначально осторожной имплементации в отечественную правовую модель, ее постепенного «прививания» к древу российского правоведения в составе «гибридной» концепции социалистического правового государства, до окончательного вытеснения всех конкурирующих концепций (таких, как концепция социалистической законности) и утверждения в качестве флагмана отечественной политико-правовой мысли на грядущие десятилетия.

\section{Библиография:}

1. Вестов Ф.А. Политико-правовые представления о правовом государстве в советский период // Известия Саратовского университета. Серия Экономика. Управление. Право. 2009. Т. 9.

2. «Свод законов СССР», т. 10, 1990 г.

3. Колюшин Е.И. Проект Конституции СССР 1990 г. // Конституционное и муниципальное право. 2014. № 4.

4. Садовникова Г.Д. Конституционные аспекты формирования российского правового государства: Автореф. дисс. ....канд. юрид. наук. М., 1993.

5. Ершов В.В. Судебная власть в правовом государстве: Автореф. дисс. ...докт. юрид. наук. М., 1992.

6. Беленов Г.Н. Советское правовое государство и личность: Состояние и развитие прав человека: Автореф. дисс. ...канд. юрид. наук. М., 1991.

7. Лисюткин А.Б. Принципы законности и их реализация в условиях формирования правового государства: Автореф. дисс. ...канд. юрид. наук. Саратов, 1992.

8. Проект Конституции Российской Федерации. Подготовлен Конституционной комиссией Съезда народных депутатов Российской Федерации: Документы и материалы. М.: Республика, 1993.

9. Текст проекта, опубликованный в газете «Федерация», 1992. № 16.

10. Текст проекта, размещенный на Интернет-сайте http://constitution.garant.ru/history/active/101203 (дата обращения -8 августа 2015 г.).

11. Текст проекта, опубликованный в газете «Московская правда», 5 мая 1993 г.

12. Горобец В.Д. Правовое государство: от истории к современности. М., 1995.

13. Мишин Г.К. Теория правового государства и вопросы уголовного права. М., 1995.

14. Правовое государство в России: замысел и реальность (к десятилетию перестройки). Круглый стол юристов, 19 апреля 1995 г. М., 1995.

15. Омельченко О.А. Идея правового государства: истоки, перспективы, тупики. Опыт исторического комментария к современной политической мифологии. М., 1994.

16. Раянов Ф.М. Введение в правовое государство. Уфа, 1994.

17. Соколов А.Н. Правовое государство. Идея, теория, практика. Курск, 1994.

18. Федоров В.П. Истоки идеи правового государства. Владивосток, 1994. 
DOI: $10.7256 / 1811-9018.2015 .8 .16129$

При цитировании этой статьи сноска на dоі обязательна

\section{Право и политика 8 (188) • 2015}

\section{References (transliterated):}

1. Vestov F.A. Politiko-pravovye predstavleniya o pravovom gosudarstve v sovetskii period // Izvestiya Saratovskogo universiteta. Seriya Ekonomika. Upravlenie. Pravo. 2009. T. 9.

2. Kolyushin E.I. Proekt Konstitutsii SSSR 1990 g. // Konstitutsionnoe i munitsipal'noe pravo. 2014. № 4.

3. Sadovnikova G.D. Konstitutsionnye aspekty formirovaniya rossiiskogo pravovogo gosudarstva: Avtoref. diss. ...kand. yurid. nauk. M., 1993.

4. Ershov V.V. Sudebnaya vlast' v pravovom gosudarstve: Avtoref. diss. ...dokt. yurid. nauk. M., 1992.

5. Belenov G.N. Sovetskoe pravovoe gosudarstvo i lichnost' :Sostoyanie i razvitie prav cheloveka: Avtoref. diss. ....kand. yurid. nauk. M., 1991.

6. Lisyutkin A.B. Printsipy zakonnosti i ikh realizatsiya v usloviyakh formirovaniya pravovogo gosudarstva: Avtoref. diss. ...kand. yurid. nauk. Saratov, 1992.

7. Gorobets V.D. Pravovoe gosudarstvo: ot istorii k sovremennosti. M., 1995.

8. Mishin G.K. Teoriya pravovogo gosudarstva i voprosy ugolovnogo prava. M., 1995.

9. Omel'chenko O.A. Ideya pravovogo gosudarstva: istoki, perspektivy, tupiki. Opyt istoricheskogo kommentariya k sovremennoi politicheskoi mifologii. M., 1994.

10. Rayanov F.M. Vvedenie v pravovoe gosudarstvo. Ufa, 1994.

11. Sokolov A.N. Pravovoe gosudarstvo. Ideya, teoriya, praktika. Kursk, 1994.

12. Fedorov V.P. Istoki idei pravovogo gosudarstva. Vladivostok, 1994. 